\begin{abstract}
Iranica
Abstracta Iranica Revue bibliographique pour le domaine irano-aryen

Volume 40-41 | 2019

Comptes rendus des publications de 2017-2018
\end{abstract}

\title{
Oliver Nicholson (ed.). The Oxford Dictionary of Late Antiquity
}

\section{Florence Jullien}

\section{(2) OpenEdition \\ 12 Journals}

\section{Édition électronique}

URL : http://journals.openedition.org/abstractairanica/50756

DOI : 10.4000/abstractairanica.50756

ISBN : 1961-960X

ISSN : 1961-960X

Éditeur :

CNRS (UMR 7528 Mondes iraniens et indiens), Éditions de l'IFRI

Référence électronique

Florence Jullien, « Oliver Nicholson (ed.). The Oxford Dictionary of Late Antiquity », Abstracta Iranica [En ligne], Volume 40-41 | 2019, document 2, mis en ligne le 30 décembre 2019, consulté le 20 avril 2021. URL : http://journals.openedition.org/abstractairanica/50756 ; DOI : https://doi.org/10.4000/ abstractairanica.50756

Ce document a été généré automatiquement le 20 avril 2021.

Tous droits réservés 


\title{
Oliver Nicholson (ed.). The Oxford Dictionary of Late Antiquity
}

\author{
Florence Jullien
}

\section{RÉFÉRENCE}

Oliver Nicholson (ed.). The Oxford Dictionary of Late Antiquity. Oxford: Oxford University Press, 2018, 1744 p. ISBN: 978-0198662778

1 Cet instrument fait la jonction entre deux dictionnaires référents déjà parus, The Oxford Classical Dictonary (2012) et The Oxford Dictionary of the Middle Age (2010). Publié en deux volumes reliés, il comporte cinq mille entrées classées par ordre alphabétique et rédigées par plus de quatre cents contributeurs internationaux. Selon les vœux de son éditeur scientifique, il répond aux critères exigeants de multidisciplinarité qui caractérisent la collection, et s'appuie sur les travaux de la recherche en cours. Il couvre ainsi tous les aspects de l'histoire (politique, militaire, religieuse, économique et sociale, etc.) et de la culture (éducation, religion, philosophie, culture matérielle, art, architecture, science, littérature), du droit et de l'administration, ainsi que de nombreux autres domaines. La zone géographique couverte par ces prospections est vaste, depuis l'Europe occidentale jusqu'à la Méditerranée, le Proche et le MoyenOrient (l'Empire perse et l'Asie centrale) entre le milieu du IIIe siècle et le milieu du VIIIe siècle de notre ère - un créneau chronologique généralement désigné sous le nom d'Antiquité tardive. La définition des contours de cette notion spatio-temporelle est encore discutée. Pour le monde iranien, M. G. Morony avait posé la question de la pertinence d'inclure l'Iran sassanide dans la période et l'histoire de l'Antiquité tardive ( Should Sasanian Iran be Included in Late Antiquity?», dans T. Daryaee [ed.], Sasanika Occasional Papers 1, 2010, p. 1-9), cette inclusion étant contestée par certains historiens qui définissent la période (250-650 ou 750) selon des critères dépendant exclusivement des données des sources issues de l'empire romain oriental. Voir à ce propos le compte rendu de R. Gyselen dans Abstracta Iranica 32-33, 2013, n 191. Elle souligne que le concept d'“Antiquité tardive" reste une construction intellectuelle : M. Morony se tient 
ainsi à une définition sur le strict argument de l'espace chronologique (III ${ }^{\mathrm{e}}-\mathrm{VII}{ }^{\mathrm{e}}$ siècles) en justifiant l'insertion de l'Iran sassanide par des similitudes avec le monde romain. On saluera cet ouvrage désormais référent sur la période.

\section{AUTEURS}

\section{FLORENCE JULLIEN}

CNRS, Mondes iranien et indien, Paris 